\title{
Exploring the Influence of Social Interaction, Pressure and Trust in a Social Media Environment on Political Participation: The Case of Occupy Central in 2014
}

\section{Wendy Chan Wing Lam, Hong Kong Baptist University, Honk Kong}

\begin{abstract}
This study explores the factors that contribute to the political participation in the context of the Facebook platform. The author investigates the influence of social interaction, pressure and trust on users' political participation in the event that happened in Hong Kong, the Occupy Central in 2014. The study allows us to identify which factor would contribute to the best in mobilizing the mass online in the social media environment. The results show that there are positive correlation of the factors, social interaction, the social pressure and trust to the political participation respectively. An important novel finding is the influence of social pressure in Facebook on political participation. This relationship reaches the statistical significance, implying that pressure should not be neglected online but rather it is more important than other factors when giving rise to the social movement. This study offers insight that the salience of social pressure in the online context, and suggesting a possible triggering outlet for the social movement.
\end{abstract}

Keywords: Occupy Central, Political Participation, Social Interaction, Social Media Trust, Social Pressure 


\section{Introduction}

In this day and age, youngsters rely on the social media platforms to obtain the most up to date information.Over $70 \%$ of online adults use Facebook and over $20 \%$ use other kinds of social media platforms, for instance, LinkedIn, Pinterest, Instagram and Twitter respectively (Pew Research, Sep 18-21, 2014). Social media platforms take a pivotal role in providing timely materials and at the same time they act as virtual places for people to interact with each other and share their thoughts and opinions. Undoubtedly, it has become public place for information gathering and even help put forward a social movement,Occupy Central, for instance, some popular Facebook pages that share the real time information about Occupy Central, Soc Rec (https://www.facebook.com/socrec) enlisted over 211, 000 likes in 2015 April; Inmedia (https://www.facebook.com/inmediahk) has gained 431,224 likes and some other pages that started up by the leaders/ activists of this social movement, for example, Joshua Wong Chi-fung has over 252, 000 likes for his personal page (https://www.facebook.com/joshuawongchifung). The likes for the page could be inferred to the users' inclination to read the materials updated by the page, once they "likes" the page, every post updated by the page would come to the top of the newsfeed eventually.Recent case, Occupy Central that took place in Hong Kong from September to December in 2014,political participation is heightened by the fact that the intense interaction in the social media platforms and the exchange of information would be the driving force for the success of this social movement, Occupy Central. In light of this, this research would touch on with the three crucial factors that are closely connected with political participation,they are social media trust and social interaction and social pressure. 


\section{Literature Review}

\section{Social Media and Social Movement}

For long, social media platforms have served an inevitable role to disseminate information. In the newspaper coverage, online media sources have grown more important (Lee, 2014). Apart from the news industry adopting the information from the online platforms, in fact, the users also rely heavily on the information given by the social networking sites.However, social media does not limit itself by offering valuable information, beyond this, they offer a public place for people to initiate and react on a social action and Occupy Central has been a timely issue to talk about. In this day and age, social movement seems inseparable from social media in the sense that it acts as a platform to gather and disseminate the information and even take the pivotal role in gathering manpower in contributing to a successful social movement. Previous research mentions that today's widespread use of the Internet and social network sites (SNS) act as locus for areas of civic and political participation (Skoric \& Poor, 2013; Willnat et al., 2013). It is also said in the prior literature that online political expression enhanced the effects of political mobile apps, traditional offline and online media, and social media on political participation and implies that there is a mobilizing role of online media in the democratic process for young adults (Yamamoto et al., 2013). More than that, Internet sites such as Youtube and Facebook have tremendously reduced the distribution costs for ordinary people (Baker, 2006) and thus the information online could freely be accessible to people from all walks of life if they have the internet access. It is also mentioned by Loginova (2014) saying that young people's political participation in the 2011 parliamentary elections that there are divisions between those who support and those who condemn the authorities, and between those who are active users of the Internet and who take part in discussion and those who are indifferent to public discussion. With the convenient access to the internet, prior research emphasizes that a number of recent studies of protest movements have implicitly 
acknowledged it through the use of terms such as "Twitter revolutions" or "Facebook revolutions" and similar (Freelon, Merritt, \& Jaymes, 2014) and also for the voting behavior is also closely linked with the online media participation in which online media use was proves positively associated with higher levels of political participation among Malaysian voters (Wong et al., 2013). Not only the social media platform itself has the information dissemination power, it is proved that social media brings about an acceleration of activists communication and the network also urged activist to report about the protest on Twitter, YouTube, and Flickr and did the hashtag about the event. The hyperlink network embedded the protest communication (Poell, 2014). In light of the above, there is a close relationship between the social media environment as well as the

\section{Trust in Social Media Platforms}

Trust is highly pertinent to social media. It is said that trust as a research concept has been examined in several social science disciplines, including sociology, social psychology, anthropology, economics, marketing and organizational behavior, (Mayer etal, 1995) and most recently, e-commerce (Bhattacherjee, 2002; Malhotra, 2004; Özgüven, 2011; Saeednia\&Abdollahi, 2012). Trust also facilitates the customers' satisfaction and thus they would develop loyalty towards the brand (Morgan \& Hunt, 1994). Internet, no matter, when looking at trust this factor, it is no longer limited to the transaction and commerce, but also the social media trust. Online safety is a continuing concern for a lot of the stakeholders and the internet, mobile phone and social networking sites enable the sharing and dissemination of personal information online. Yet there are still number of online behaviors, for instance, sharing personal information, interacting with strangers which are considered to be risky due to their potential to result in a variety of negative experiences (Bryce \& Fraser, 2014). There are myriad of researches explore the impact of social media platforms, for example Twitter, shed 
light on the impact of Twitter trust on users' intention to continue using the platform and to follow brands that are hosted on Twitter (Pentina et al., 2013). On the other hand, social media platform serve as important bridge for people to connect with each other. It is said networks have always been part of society to help people navigate within groups or between groups (Castelles, 2000) so it is crucial for us to dig a deeper look on how trust in the social media platform form in order to put forward a social movement. In addition, trust is well tested under the construct of 3 dimensions, which are ability, integrity and benevolence in the context of e-commerce(Bhattacherjee, 2002).In his research, he explored over 10 prior literature talking about trust dimension and finally come up with his own trust definition. Ability, in his definition, refers to the trustor's perception of trustee's competencies and knowledge salient to the expected behavior; integrity, is defined as the domain ability that is not adequate for building trust, trustee must also be relied on to fulfill obligations to trustors; and lastly benevolence is the extent to which a trustee is believed to intend doing good to the trustor, beyond its own profit motive. While we put into today's context, it is still largely relevant. So what is trust within the social media context? Previous research mentions as trusting relationships develop inside a network, actors build up reputation of trustworthiness that may become important information for other actors in the network (Tsai \& Ghoshal, 1998). Traditionally, dense social networks, personal contacts, group membership, and social class have been considered the direct sources of trust (Nonaka, 1994) and also online social network (Rahman et al., 2011). In light of this, it is believed in the network society, social media platforms plays a dominant role in providing information while the users trust the information that provided by the platforms every minute. The trust attaches to it would certainly give a rise to the social movement participation because it is deemed to be a persuasion and a proof that what is happening outside. 


\section{Social Interaction in Social Media Platforms}

In the prior literature, it is highlighted that computer supported social networks (CSSNs) have strong societal implications and enhance the global connectivity (Wellman et al., 1996). Previous findingalso shows that the mediating role for social connections maintained in online social networks highlight the importance of trust and close friendship ties(Skoric \& Poor, 2013) and social interaction even facilitates the quality of knowledge sharing and knowledge quality (Chiu etal., 2006). People's social ties are channels for information and resource flow (Tsai \& Ghoshal, 1998). It is said that people share photos, knowledge, and personal feelings, and receive replies, comments, and feedback in which social media could now be used to build learning communities (Chan \& Ma, 201; Ma \& Yuen, 2010; 2011).In addition, prior literature postulates that quality Web features, and user instrumental and relational need fulfillment are antecedents of interpersonal trust and platform credibility (Hung et al., 2011). Besides facilitating the learning environment, for the online services, people are easily able to share their good and bad experiences with various products and services with a large number of strangers in addition to their friends. These experience-sharing communities try to encourage social interaction among people to facilitate experience sharing and dissemination (Kim $\&$ Phalak, 2012). Abovementioned researches show that there are frequent interactions within the internet and other online environments. Previous literature also points out in the logic of connective action, "various personal communication technologies that enable sharing these themes, whether through texts, tweets, social network sharing, or posting YouTube mashups, the communication process itself often involves further personalization through the spreading of digital connection (Bennett \&Segerberg, 2012). Under such phenomenon, while putting the example of social movement Occupy Central in Hong Kong in this assumption, it is foreseeable to see that "sharism" also take place in social mobilization.In addition, researcher also points out that internet news use moderates the negative effect of selective online 
interaction and indirectly contribute to political diversity (Jun, 2012). More than that, the internet plays a prominent role in making traditional forms of political engagement easier and more convenient for voters, like using a campaign website to donate money, sign up for news mailings, or request the delivery of a yard sign is arguably much easier than travelling to the campaign's headquarters to do it in person (Hoffman et al., 2013). Base on the prior literatures, social interaction is not limited to the offline interactions with people in real life but also the online platforms as well. Yet, why does the online platforms as well as the interaction become important factor for contributing the social movement and what kind of effect will be generated?

\section{Social Interaction and Social Pressure}

When we talk about pressure, we often find it in the school context where teenagers or people would find a difficult situation in handling the pressure from different perspectives, academic results, career performance, family problems and the relationship with their peers. For instance, parents not only use these new technologies to communicate with their children, but also to monitor their online behaviors (Ball etal., 2013). Yet, one aspect, I would like to highlight here is the pressure that youngster or users online would encounter. There is prior analysis emphasizes on how the social media have differential and interactive relationship on political participation. It is found that political conversation moderated the relationships among different types of news activities and participation, and most importantly, effects of news activities on political participation increased with the frequency with which people talked about politics on social media (Hyun \& Kim, 2015). Furthermore, it is put forward by previous literature that social media use for social interaction does not have direct influence in people's political engagement, but rather an indirect effect by means of citizens themselves politically (Gil de Zúñiga et al., 2014). Other study also found that political engagement among the 
respondents increases with online political participation and thus it set a tone for us to think about what interactions bring about, for instance, pressure that would contribute to the success of social movement?

Therefore base on the above arguments, we hypothesize that:

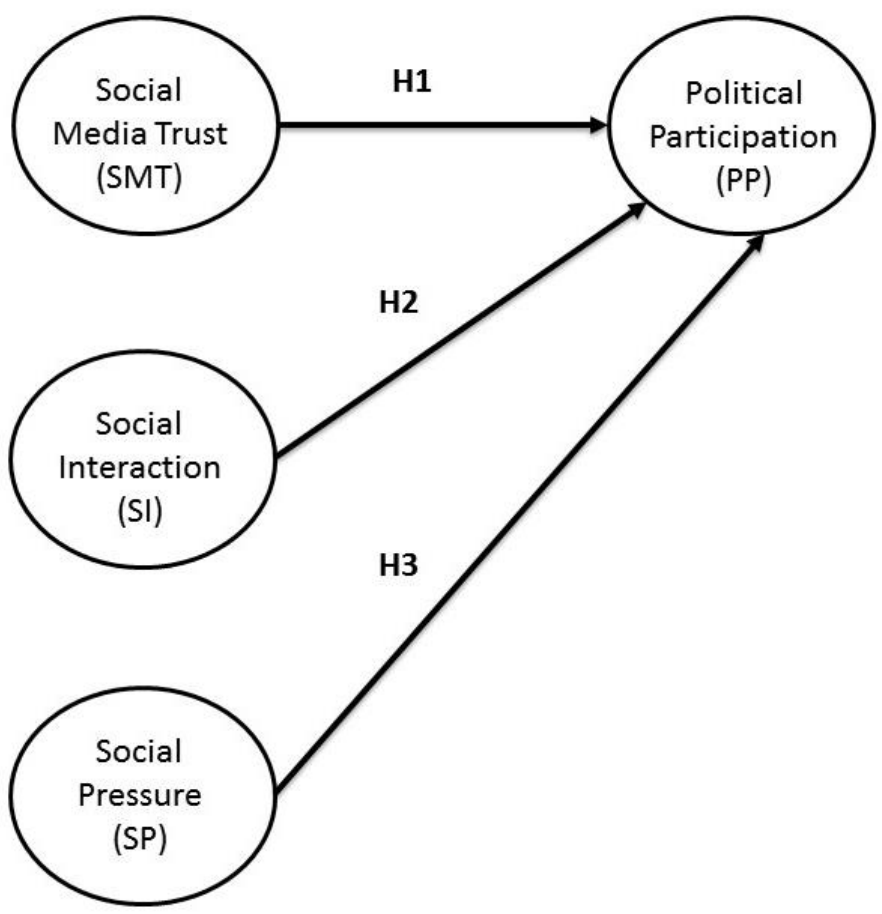

Fig 1.Proposed model of the factors constituting the political participation

H1. The more perceived social media trust an individual has in a particular social media environment, the more they would like to take part in political participation.

H2. The greater the social interaction in a social media environment, the more they would like to take part in political participation.

H3. The greater the social pressure in a social media environment, the more they would like to take part in political participation.

\section{Methods}

In this study, the subjects are all undergraduate students using social media tools. They will 
answer a set of questions about their experiences on commonly used social media sites. Social sites such as Facebook, Twitter, and blogs, are platforms that allow people to communicate with friends. These platforms are free and open toanyone who registers as a member.A questionnaire survey was used to investigate whether trust and social interaction on these sites are associated with politicalparticipation.

\section{Participants}

Participants were 176 undergraduate students, female accounted for 130 and male 46 from local universities in Hong Kong. Participants were year 1 to year 4 students and identified as local (91.5\%), mainland (8\%) and international students $(0.6 \%)$.

\section{Measurement Items}

The questionnaire are mostly adapted from a previously validated scale. Specifically, nine items exploring social media trust (SMT), four items exploring social interaction (SI), four items exploring social pressure (SP) and seven items exploring political participation (PP)will be included in the questionnaire. All of the items weremeasured on a 7-point Likert scale, with las "strongly disagree" and 7 as "strongly agree." The subjects were asked to self-reporton their usage of the most common social media. They were asked to assess their use according to three categories: frequency per month, duration per month, duration of each login. In the first part of the questionnaire, the subjects wereasked to give their demographic data, including sex, age, net knowledge, and number of years since they started to surf the net.

\section{Findings}




\section{Characteristics of the Sample}

For the exploratory stage, 176 completed responses were collected. They are mostly locals (91.5\%), mainland students contribute to the total of $8 \%$ and the international students would be of the total of $0.6 \%$. Among them, there are altogether 125 Year 2 students (71\%), year three students $(22.2 \%)$, year one student $(2.8 \%)$ and the year four students only contributes to the total of $(0.6 \%)$. These demographics reflect the internet knowledge and internet experience of the respondents. It shows that most of them think they have fair (40.9\%) and good $(51.1 \%)$ internet knowledge and $6.8 \%$ of the people think they have reach the expert level of internet knowledge. Over $98 \%$ of the sample have more than 3 years of using internet experience. In addition, the respondents answered according to their habitual practice of using Facebook. Over $85 \%$ of them use Facebook many times a day and only $1.1 \%$ of them using Facebook less than once a day. Each time they logged into the account, over $59 \%$ of them will spend over 30 minutes on Facebook, $15.9 \%$ of them would spend $20-30$ minutes per day, $13.6 \%$ of them use Facebook for 10-20 minutes and only $10.2 \%$ would spend les 10 minutes per login. This suggest that most of them are heavy users of Facebook.

\section{Relationship between Variables}

Reliability and validity testing of the variables

We tested the reliability and validity of the instrument. Validity is the degree to which a measure accurately represents what it is supposed to represent, and reliability is the degree to which an observed variable measures the "true" value and is "error free" (Hair et al., 2010). Cronbach's alpha is generally the most appropriate reliability measure for survey research that involves a range of possible answers for each item (McMillan \&Schmacher, 1989). Mostof the constructs met the reliability criteria (alpha>0.70) recommended in the literature (Nunnally\& Bernstein, 1994), in which the results show that social interaction (0.8), 
ability (0.81), integrity (0.73), benevolence (0.61), social pressure (0.68) and offline participation (0.87).

\section{Instrument validation}

Discriminant validity is demonstrated if an item correlates more highly with items within the same factor than with items in a different factor (Campbell \& Fiske, 1959). The inter-item Pearson correlation coefficients shown in Table 1 depict a discriminant validity in which the inter-item coefficients within each measurement construct are much higher than the correlations across constructs.A Pearson correlation analysis was conducted to find out the correlations between each variables. The results are summarized in Table 1. Social media trust, including three dimensions, they are integrity $(r=0.145, n s)$, benevolence $(r=0.230, p<$ $0.01)$ and ability $(r=0.284, p<0.01)$, are significantly positive correlated to the participation of Occupy Central. Hypothesis one was then partly supported.Social Interaction $(r=0.218, p<$ 0.001) is significantly positively correlated to the participation of Occupy Central. Thus, hypothesis two was supported.Hypothesis three was supported by the positive correlation between social pressure $(r=0.301, p<0.01)$ and participation of Occupy Central.

Table 1.Pearson's bivariate Correlations among All Variables 


\section{Correlations}






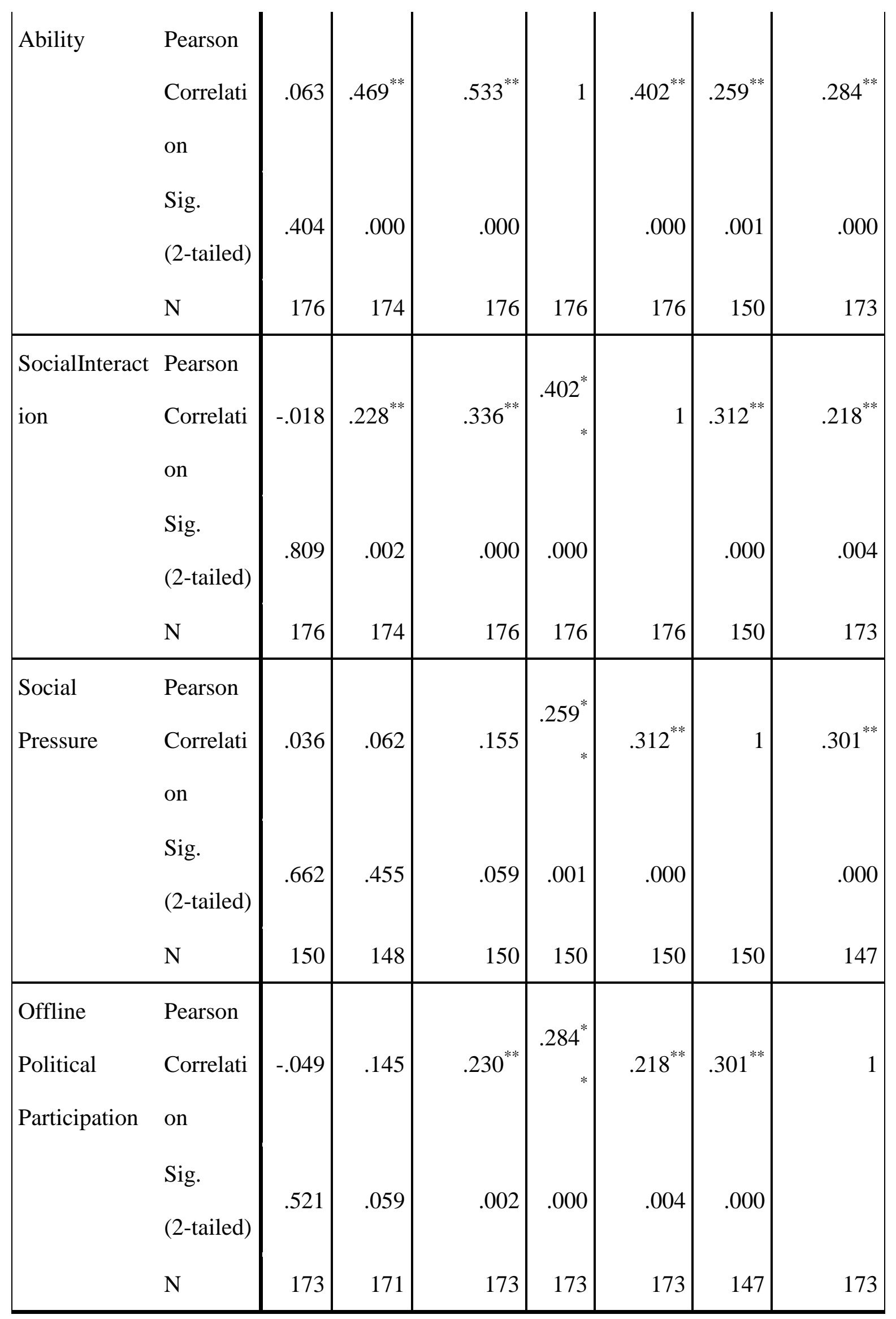


$* \mathrm{p}, 0.05 ; * * \mathrm{p}<0.01 ; * * * \mathrm{p}, 0.001$

Hierarchical Regression analysis was used to analysis the relationships among independent variables and dependent variables by adding predictors in different hierarchies. Result is shown in the Table 2.The social pressure within the social media platform $(\beta=0.263, t=3.111, p<$ 0.05) is a significant predictor to the participation of Occupy Central. However, the social interaction within the social media platform $(\beta=0.045, t=0.512, p>0.05)$ is not a significant predictor to the participation of Occupy Central and Trust's three dimensions, including integrity $(\beta=0.007, t=0.062, p>0.05)$, benevolence $(\beta=0.013, t=0.108, p>0.05)$ and ability $(\beta=0.148, t=1.503, p>0.05)$ are also not significant predictors to the participation of Occupy Central.

Table 2.Regression Analysis Predicting the Political Participation

\begin{tabular}{|c|c|c|c|c|c|}
\hline \multicolumn{6}{|c|}{ Coefficients $^{\mathrm{a}}$} \\
\hline & \multicolumn{2}{|c|}{$\begin{array}{c}\text { Unstandardized } \\
\text { Coefficients }\end{array}$} & \multirow{2}{*}{$\begin{array}{l}\text { Standardized } \\
\text { Coefficients } \\
\text { Beta }\end{array}$} & \multirow[b]{2}{*}{$\mathrm{t}$} & \multirow[b]{2}{*}{ Sig. } \\
\hline & B & Std. Error & & & \\
\hline $\begin{array}{l}\text { Social } \\
\text { Interaction }\end{array}$ & .049 & .095 & .045 & .512 & .610 \\
\hline Integrity & .007 & .116 & .007 & .062 & .951 \\
\hline Benevolence & .019 & .173 & .013 & .108 & .914 \\
\hline Ability & .185 & .123 & .148 & 1.503 & .135 \\
\hline Social Pressure & .278 & .089 & .263 & 3.111 & $.002 *$ \\
\hline
\end{tabular}


$* \mathrm{p}, 0.05 ; * * \mathrm{p}<0.01 ; * * * \mathrm{p}, 0.001$

\section{Discussion and Theoretical Implications}

\section{Social Pressure Generated from the Social Media Platform Contribute the Success of}

\section{Occupy Central}

Social interaction online would definitely cause unavoidable social pressure that leads to offline political participation. In the case of Occupy Central, social pressure has been the key factor to contribute the online political activity, especially teenagers, university students and other relatively younger generation who are heavy users of Facebook platform that is also highly related to the factor of social media trust. Facebook pages, ranging from $\operatorname{Soc} \operatorname{Rec}(212$, 685 likes), Scholarism (316, 076 likes), Joshua Wong (252,391 likes), etc., they have enlisted public's support, especially the youth's supports. They now even trust the information online more than the traditional media.Users tend to trust the social media platforms, the information that disseminated by their peers would also imply their own stance, the more the people that within the platforms support the events, your opinions would be easily swayed by the stance of your peers. More than that, social media platforms are mostly free and the young people could easily get access to it. Once you have the internet access and you have registered an account, they could interact with their peers. More to note is that there are different pages with a wide range of variety. Take an example, if you support the action of the police to force the people out of the occupied area, you would tend to give a like to the page initiated by the police. Yet, if you are more inclined to support the public's act in voicing out their petitions, then you can like the page initiated by the public and even share the posts on your personal page. Yet, the unconscious pressure would be found within the platforms. While your circle of friends take the stance to support the public's act in Occupy Central, they would disseminate the information and saying they have been in the occupied area, they would also get involved in the 
group's conversation by using the Facebook chat function that is also talking about the participation of Occupy Central and even persuade you to take part in the social mobilization as well. The pressure is heightened in this social movement in the way that the initiator of this social movement is by a group of college and university students in Hong Kong. The institutes in Hong Kong do not show their political stance in the beginning of this social movement, and the students boycott the classes according to their own will. Therefore, most of the teenagers took part in such event and there is a high circulation of the information online, especially on Facebook, including how they stayed overnight in the occupied area, how they organize the donated materials in each station of the area and the byproducts of such movement, say the art pieces gain a lot of supports online.

\subsection{Trust Formed withinSocial Media Platform Constitutes Communication (PCC)}

Social Media Trust helps develop the social interaction, thus, helps put forward the political participation. It is undeniable to say that social media platforms can motivate users and build their trust to improve their attitudes which in turn will increase users' willingness in making positive comments on product and services. Hence, this time, in Occupy Central movement, people trust the platform and they start to use the platform to share their photos, like their page as to follow them and even start up conversation groups initially to call for an occupy action. Some groups even ask for resources in the group, this reliance on social media platform should not be under estimated because we can actually see there are aids generated by the frequent interaction among the users and public put trust on the information so as to offer a helping hand. The mobilization power of the people is definitely heightened by the social media trust eventually. 


\section{Political Participation is affected by Different Factors from the Social Media Platform}

Political participation is correlated with social pressure, social; interaction and social media trust respectively. Social Media Trust helps put forward the political participation since people place trust on the platform, therefore, they interact.Yet, for trust alone, if no activities take place, for example, situational involvement and self-efficacy, then political participation would not take place (Wen \& Cui, 2014). For the social interaction, the zenith time for the most intense interaction among users takes place at the social media platform at the time of Occupy Central, 2014. Again, some renowned pages are shared by people and among friends very intensively and the messages are all around the platforms. Result shown above state that social pressure is a key factor leading to Participation in the case of Occupy Central, 2014,this implies young participants, who are also the heavy users of social media platforms, easily feel pressurized after they read the information shared by their friends, in forms of photos, comments, inbox messages and group pressure (secondary school support group)

\section{Pressure as an Identity to Safeguard Hong Kong among TeenagersMakes a Success for Occupy Central}

Unlike other social movements, Occupy Central is a movement that paralyze the operation of Hong Kong society. Financial sectors, no matter they are in large scale or small scale, they showed discontent towards this social movement because this hamper the development of economy if tourists are afraid to come and investors would not consider Hong Kong as the place to invest money on. Owing to this, politicians and businesses sectors voice their concern in the media. Yet, the Facebook platform has been flooded by the information to support Occupy Central and the active users of Facebook are usually the young ones, namely the college students as well as the university students. They are the ones who heavily rely on the platforms to connect with their peers. In the context of Occupy Central, trust for the platform 
only facilitates the information dissemination in which people trust the information online, yet it cannot help the participation of this political movement. On the other hand, social interaction would further enhances how people share their views on this political movement, thus, the peer pressure is formed. From the result that shown, social interaction, trust for the platforms and peer pressure could be positively correlated to the political participation offline, yet by further refining the result through regression, it is the pressure that makes this movement a zenith in the end especially most of the participants are teenagers and heavy users in the Facebook.

\section{Conclusions}

This study examined three constructs: social pressure, social interaction, and social media trust to explain how political participation can be accelerated. The results showed that the above mentioned factors are key determinants in predicting users' offline political participation. This study provides a concrete model with empirical evidence to support further studies of this phenomenon.

\section{Limitations and further studies}

There were a number of limitations in this study. Although we believe thatundergraduate students are a good proxy for the general user population, as teenagers are very active users of social media, further studies are needed to determine the generalizability of the results. The sample in future studies should be more diverse in terms of age and work experience. More than that, there are also other factors that contribute to the participation offline in different countries; for example, political participation could be predicted by offline petitions and economic conditions, like the unemployment rate. Additionally, this study would only shed light on Occupy Central took place in Hong Kong.

\section{Acknowledgement}


This research would not be successful without the help from Mr. Ng Yu Leung for his kind help on data collection and analysis.

\section{Questionnaire-items:}

\section{Background Information}

1. Gender

2. Age

3. Internet Knowledge: A. Beginners B. fair C. Good D. Expert

4. Internet Experience: A. $\leq 3$ year B. $>3$ years:

5. Social Media Usage: A. Many times per day B. Once per day C. Less than once per day

6. Social Media Usage: A. More than an hour per day B. One hour per day C. Less than one hour per day

7. Time for each log in: A. >30 min B. 20-30 min C.10-20 min D. $<10$ minutes

\section{Social Interaction (SI) (Nahapiet\&Ghoshal, 1998; Tsai\&Ghoshal, 1998)}

1. I maintain close social relationships with other people using social media.

2. I spent a lot of time interacting with other users.

3. I know other users on a personal level

4. I have frequent communication with other users.

\section{Social Media Trust (SMT) Scale (Bhattacherjee, 2002)}

\section{Ability}

1. Social media platform has the skills and expertise to present us with proper information online. 
2. Social media platformhas access to the informationneeded to be known by us.

3. Social media platform has the ability to meet users' needs.

\section{Integrity}

4. Fairness in transaction: Social media platform is fair in its conduct of sharing information.

5. Fairness in data usage: Social media platform is fair in its use of private user data collected during the social movement.

6. Fairness in service: Social mediaplatformis fair in its customer service policies.

\section{Benevolence}

7. Empathy: Social media platform is open and receptive to users' needs.

8. Benevolence: Social media platform keeps its customers' best interest in mind during the social movement.

9. Resolving concerns: Social media platformmakes good-faith efforts to concerns address most customer concerns

\section{Social Pressure (SP)}

1. When people spread the message about umbrella revolution on the social media platforms, I would feel pressurized.

2. When people spread the message about umbrella revolution on the social media platforms, I think I have the obligation to share the message as well.

3. If people start a conversation with me on the platform talking about umbrella revolution, I think I should join in their conversation.

4. If I see people participate in the umbrella revolution in the platform, I also think I 
should join as well.

\section{Political Participation (PP)(Skoric\& Poor, 2013)}

1. Boycotted class

2. Went out on the protest area

3. Did volunteer work (e.g. cleaned the protest area)

4. Designed protest arts (e.g. posters)

5. Stayed or slept overnight on the protest area

6. Called other people to donate materials to the protest area

7. Circulated the information of occupied area verbally with friends or family

5. Spoke publicly about the social movement 


\section{References}

Baker, C. E. (2006). Media Concentration and Democracy: Why Ownership Matters. Cambridge University Press.

Ball, H., Wanzer, M. B., \&Servoss, T. J. (2013). Parent-Child Communication on Facebook: Family Communication Patterns and Young Adults' Decisions to "Friend" Parents. Communication Quarterly, 61(5), 615-629.

Bennett, W. L., \&Segerberg, A. (2012). The Logic of Connective Action: Digital Media and the Personalization of Contentious Politics. Information, Communication \& Society, 15(5), 739-768.

Bhattacherjee, A. (2002). Individual Trust in Online Firms: Scale Development and Initial Test.Journal of Management Information Systems19, 211-241

Bryce, J., \& Fraser, J. (2014).The Role of Disclosure of Personal Information in the Evaluation of Risk and Trust in Young Peoples' Online Interactions.Computers in Human Behavior, 30, 299-306.

Campbell, D.T.,\& Fiske, D.W.: Convergent and Discriminant Validation by the Multitrait Multimethod Matrix. Psychological Bulletin 56, 81-105 (1959).

Castelles, M. (2000) The Network Society, $2^{\text {nd }}$ edn, Oxford: Blackwell.

Chai, S., Das, S., \&Rao, H.R.: Factors Affecting Bloggers' Knowledge Sharing: An

Investigation across Gender.Journal of Management Information Systems 28, 309-342 (2011)

Chan, W. W. L., \& Ma, W. W. K. (2013). Exploring the Influence of Social Ties and Perceived Privacy on Trust in a Social Media Learning Community. In Hybrid Learning and Continuing Education, 134-144. Springer Berlin Heidelberg.

Chiu, C.-M., Hsu, M.-H., \&Wang, E.T.G. (2006).Understanding Knowledge Sharing in Virtual Communities: An Integration of Social Capital and Social Cognitive Theories.DecisionSupport Systems 42, 1872-1888. 
Freelon, D., Merritt, S., \&Jaymes, T. (2014). Focus On The Tech. Digital Journalism,3 (1), $1-17$.

Gefen, D., Karahanna, E., \&Straub, D.W (2003). Trust and TAM in online shopping: An integrated mode. MIS Quarterly 27, 51-90.

Gil de Zúñiga, H., Molyneux, L., \& Zheng, P. (2014). Social media, Political Expression, and Political Participation: Panel Analysis of Lagged and Concurrent Relationships. Journal of Communication, 64(4), 612-634.

Hair, J.F., Black, B., Babin, B., \& Anderson, R.E. (2010).Multivariate Data Analysis: A Global Perspective. Upper Saddle River: Pearson.

Hung, K., Li, S.Y., Tse, D.K.: Interpersonal trust and platform credibility in a Chinese multi brand online community: Effects on Brand Variety Seeking and Time Spent. Journal of Advertising 40, 99-112 (2011)

Hoffman, L. H., Jones, P. E., \& Young, D. G. (2013). Does My Comment Count? Perceptions of Political Participation in an Online Environment.Computers in Human Behavior, 29(6), 2248-2256.

Hyun, K. D., \& Kim, J. (2015).Differential and Interactive Influences on Political Participation by Different Types of News Activities and Political Conversation through Social Media. Computers in Human Behavior, 45, 328-334.

Kim, Y.A., \&Phalak, R. (2012). A Trust Prediction Framework in Rating-based Experience Sharing Social Networks without a Web of Trust. Information Sciences 191, 128-145

Lee, F. L. F. (2012). News from YouTube : Professional incorporation in Hong Kong Newspaper Coverage of Online Videos. Asian Journal of Communication 22(1), 1-18. Loginova, K. (2014). Young People's Political Participation in the 2011 Parliamentary Elections.Russian Education \& Society, 56(3), 54-79.

Ma, W.W.K., \&Yuen, A.H.K. (2011).Understanding Online Knowledge Sharing: An 
Interpersonal Relationship Perspective.Computers \& Education 56, 210-219

Ma, W.W.K., \&Yuen, A.H.K. (2010).Understanding online knowledge sharing: An exploratory theoretical framework. In: Tsang, P., Cheung, S.K.S., Lee, V.S.K., Huang, R. (eds.) ICHL2010. LNCS, vol. 6248, pp. 239-248. Springer, Heidelberg

Malhotra, N.K., Kim, S.S., \&Agarwal, J. (2004). Internet Users' Information Privacy Concerns (IUIPC): The Construct, the Scale, and a Causal Model. Information Systems Research $15,336-355$.

Mayer, R.C., Davis, J.H., \&Schoorman, F.D. (1995).An Integration Model of Organizational Trust.The Academy of Management Review 20, 709-734

McMillan, J.H., \&Schmacher, S. (1989).Research in Education: A Conceptual Introduction. HarperCollins Publishers.

Morgan, R. M., \& Hunt, S. D. (1994). The Commitment-trust Theory of Relationship Marketing. The Journal of Marketing, 20-38.

Nahapiet, J., \&Ghoshal, S.: Social Capital, Intellectual Capital, and the OrganizationalAdvantage. Academy of Management Review 23, 242-266 (1998)

Nonaka, I. (1994).A Dynamic Theory of Organizational Knowledge Creation.OrganizationScience 5, 14-37

Nunnally, J.C., \&Bernstein, I.H. (1994).Psychometric Theory. McGraw-Hill, New York Özgüven, N. (2011). Analysis of the Relationship between Perceived Security and Customer Trust and Loyalty in Online Shopping.Chinese Business Review 10, 990-997.

Pentina, I., Zhang, L., \&Basmanova, O. (2013). Antecedents and Consequences of Trust in a Social Media Brand: A Cross-cultural Study of Twitter. Computers in Human Behavior, 29(4), 1546-1555.

Poell, T. (2014). Social Media and the Transformation of Activist Communication: Exploring the Social Media Ecology of the 2010 Toronto G20 Protests. Information, 
Communication \& Society, 17(6), 716-731.

Rahman, M.S., Haque, M.M., \& Khan, M.B.K. (2011).The Influence of Privacy, Trust towardsOnline Social Network: An Exploratory Study on Bangladeshi Customers Perception.European Journal of Economics, Finance and Administrative Sciences, $126-134$

Saeednia, H., Abdollahi, H. (2012). Factors Affecting Client Trust in Online Banking - A Case Study of Saman Bank. International Journal of Economics \& Business Modeling 3, $149-151$

Skoric, M. M., \& Poor, N. (2013). Youth engagement in Singapore: The interplay of social and traditional media. Journal of Broadcasting \&Electronic Media 57, 187-204.

Tsai, W., \&Ghoshal, S. (1998). Social Capital and Value Creation: The Role of Intrafirm Networks.Academy of Management Journal 41, 464-476

Wellman, B., Salaf, J., Dimitrova, D., Garton, L., Gulia, M., \&Haythornthwaite, C. (1996).Computer Networks as Social Networks: Collaborative Work, Telework, and VirtualCommunity. Annual Review of Sociology 22, 213-238..

Wen, N., \& Cui, D. (2014).Effects of Celebrity Involvement on Young People's Political and Civic Engagement.Chinese Journal of Communication, 7(4), 409-428.

Willnat, L., Wong, W. J., Tamam, E., \& Aw, A. (2013). Online Media and Political Participation: The case of Malaysia. Mass Communication and Society, 16(4), 557-585. Yamamoto, M., Kushin, M. J., \&Dalisay, F. (2013). Social Media and Mobiles as Political Mobilization Forces for Young Adults: Examining the Moderating Role of Online Political Expression in Political Participation. New Media \& Society, 1461444813518390. 